\title{
A NOTE ON THE MOMENT INEQUALITIES FOR STOCHASTIC INTEGRAL
}

\author{
YounG-Ho Kim
}

Abstract. In this paper, we shall apply Itô formula to establish several moment inequalities for stochastic integrals. These will demonstrate the powerfulness of the Itô formula.

Mathematics subject classification (2010): 60G46, 60H05.

Keywords and phrases: Itô formula, moment inequality, stochastic integral, Martingale.

\section{REFERENCES}

[1] D. L. Burkholder, Sharp inequalities for martingales and stochastic integrals, in: Colloque Paul Léy sur les processus stochastiques, Astérisque 157-158 (1988), pp. 75-94.

[2] D. L. BURKHOLDER, Strong differential subordination and stochastic integration, Ann. Probab. 22 (1994), pp. 995-1025.

[3] Y. J. Cho, S. S. Dragomir, Y.-H. Kim, A note on the existence and uniqueness of the solutions to SFDEs, J. Inequal. Appl. 2012:126 (2012), pp. 1-16.

[4] C. CHOI, A weak-type submartingale inequality, Kobe J. Math. 14 (1997), pp. 109-121.

[5] X. Mao, Stochastic Differential Equations and Applications, Horwood Publication, Chichester (2007).

[6] X. Mao, Y. Shen, C. YUAn, Almost surely asymptotic stability of neutral stochastic differential delay equations with Markovian switching, Stoch. Process. Appl. 118 (2008), pp. 1385-1406.

[7] Y.-H. KIM, An estimate on the solutions for stochastic functional differential equations, J. Appl. Math. Informatics 29 (5-5) (2011), pp. 1549-1556.

[8] X. LI, X. FU, Stability analysis of stochastic functional differential equations with infinite delay and its application to recurrent neural networks, J. Comput. Appl. Math. 234 (2010), pp. 407-417.

[9] A. OsȨKOWSKI, Inequalities for martingale transforms and related characterizations of Hilbert spaces, Statist. Probab. Lett. 82 (2012), no. 1, pp. 186-190.

[10] Y. REN, S. LU, N. XIA, Remarks on the existence and uniqueness of the solution to stochastic functional differential equations with infinite delay, J. Comput. Appl. Math. 220 (2008), pp. 364-372.

[11] Y. REN, N. XIA, Existence, uniqueness and stability of the solution to neutral stochastic functional differential equations with infinite delay, Appl. Math. Comput. 210 (2009), pp. 72-79.

[12] F. WEI, K. WANG, The existence and uniqueness of the solution for stochastic functional differential equations with infinite delay, J. Math. Anal. Appl. 331 (2007), pp. 516-531. 